This item was submitted to Loughborough's Research Repository by the author.

Items in Figshare are protected by copyright, with all rights reserved, unless otherwise indicated.

\title{
Was it different the second time? An empirical analysis of contagion during the crises in Greece 2009-15
}

PLEASE CITE THE PUBLISHED VERSION

https://doi.org/10.1111/twec.12553

\section{PUBLISHER}

(c) Wiley

\section{VERSION}

AM (Accepted Manuscript)

\section{PUBLISHER STATEMENT}

This is the peer reviewed version of the following article: BIRD, G. ...et al., 2017. Was it different the second time? An empirical analysis of contagion during the crises in Greece 2009-15. The World Economy, 40(12), pp. 2530-2542, which has been published in final form at https://doi.org/10.1111/twec.12553. This article may be used for non-commercial purposes in accordance with Wiley Terms and Conditions for Use of SelfArchived Versions.

\section{LICENCE}

CC BY-NC-ND 4.0

\section{REPOSITORY RECORD}

Bird, Graham, Wenti Du, Eric J. Pentecost, and Thomas Willett. 2019. "Was It Different the Second Time? an Empirical Analysis of Contagion During the Crises in Greece 2009-15". figshare.

https://hdl.handle.net/2134/27172. 


\title{
Was It Different the Second Time? An Empirical Analysis of Contagion during the
}

\section{Crises in Greece 2009-15}

\author{
Graham Bird*** Wenti Du*****Eric Pentecost**** and Thomas Willett*** \\ *Claremont Graduate University ** Claremont McKenna College \\ $* * *$ Loughborough University $* * * *$ Akita International University
}

\begin{abstract}
Over the period between end-2009 and end-2015 Greece experienced two discernible financial crises. This article undertakes a correlation analysis of risk premia to investigate the nature and extent of contagion from these crises to other selected Euro-zone countries. A commonly expressed view is that the effects of the second crisis were more muted since the systemic risks were seen by markets as being lower. However, using a rolling correlation model, a DCC-GARCH model and a t-copula model we find that this is not the case. Broadly speaking, the contagion effects of the second crisis were at least as large as those associated with the first one.
\end{abstract}




\section{Introduction}

A potential cost of the increasing financial integration that the Euro-zone embodies is that it may bring with it greater exposure for member countries to contagion from crises elsewhere in the currency area. Just such a threat has existed in the period since 2009 following the economic and financial crisis in Greece. A substantial amount of research has been undertaken that has examined the contagion effects of the crisis. However, this has tended to treat the crisis as one event. We contribute to this literature by arguing that there have been two, largely distinct, Greek crises. The second one was associated with the rise to power of the Syriza party in 2015. Most of the previous studies were completed before this second episode. We investigate the extent to which the degree and pattern of contagion differed between this crisis and the first one that had erupted in 2009.

A popular view emerged at the time that the contagion effects of this second crisis would be much smaller since risk premia in interest rates had declined substantially and the notion that the entire Euro-zone would collapse had diminished. According to this view, Greece was now regarded by markets as a special case with only modest implications for other Euro-zone countries.

In this paper we examine the size and effects of the two Greek crises in terms of their association with risk premia on government debt in other Euro-zone countries. In particular we focus on the other members of what was often referred to as the PIIGS group (Portugal, Ireland, Italy, Greece and Spain) and compare the effects on them with the effects on two 'core' members of the Euro-zone (France and the Netherlands). Our specific concern is to investigate how the contagion effects of the second crisis compared with those of the first one. Here we use contagion in the broad sense of the term referring to the way in which effects spread from one country to others. We do not attempt to determine what part of this broad contagion resulted from 'pure contagion' as compared with the other forms of contagion such as 'wake-up call contagion' and 'shift contagion' that have been discussed in the literature (see, for example, Ludwig, 2014; Giordano et al., 2013). 
The paper is organized as follows. Section 2 identifies the two crises in Greece and provides a brief description of them. Section 3 summarizes the currently available literature on the contagion effects of crises in Greece and explains how we add to it. Section 4 explains the data we use and the methodology we adopt. Section 5 presents and discusses the results. Section 6 offers some concluding remarks that place our study in a broader context.

\section{Crises in Greece}

Chart 1 provides an overall picture of the long-term government bond yields of Greece, Ireland, Portugal, Spain, Italy, France, the Netherlands and Germany from October 19, 2009 until November 19, 2015. Yields had generally been stable and low up until the global financial crisis in 2007/08, averaging between 4.37 per cent and 4.73 per cent. The situation in many Euro-zone countries including Ireland, Portugal, Spain and Italy deteriorated after 2009, but the most dramatic increase in yields occurred in Greece. This followed the revelation in October 2009 that the Greek fiscal deficit was considerably higher than had previously been reported. A visual inspection of Chart 1 suggests that there were two discernible crises in Greece over the period 2009-15.

Subsequent to the provision of an initial bail-out package in May 2010, a second package worth $€ 246$ billion was agreed in February 2012. In March 2012, continued sovereign debt restructuring in Greece and, perhaps more strategically, a statement by the President of the European Central Bank, Mario Draghi, in July 2012, that the ECB would do "whatever it takes" to save the euro, were associated with a general reduction in bond yields. As indicated by Chart 1, the acute phase of the crisis seemed to be over. In April 2013, the Greek Parliament approved a reform bill to implement further economic reforms, and at the end of November 2013, Moody's upgraded Greece's credit rating. In May 2014, Fitch also upgraded it. 
Chart 1. Long-Term Bond Yields of Greece, Ireland, Italy, Portugal, Spain, France, the Netherlands and Germany from October 19, 2009, to November 19, 2015.

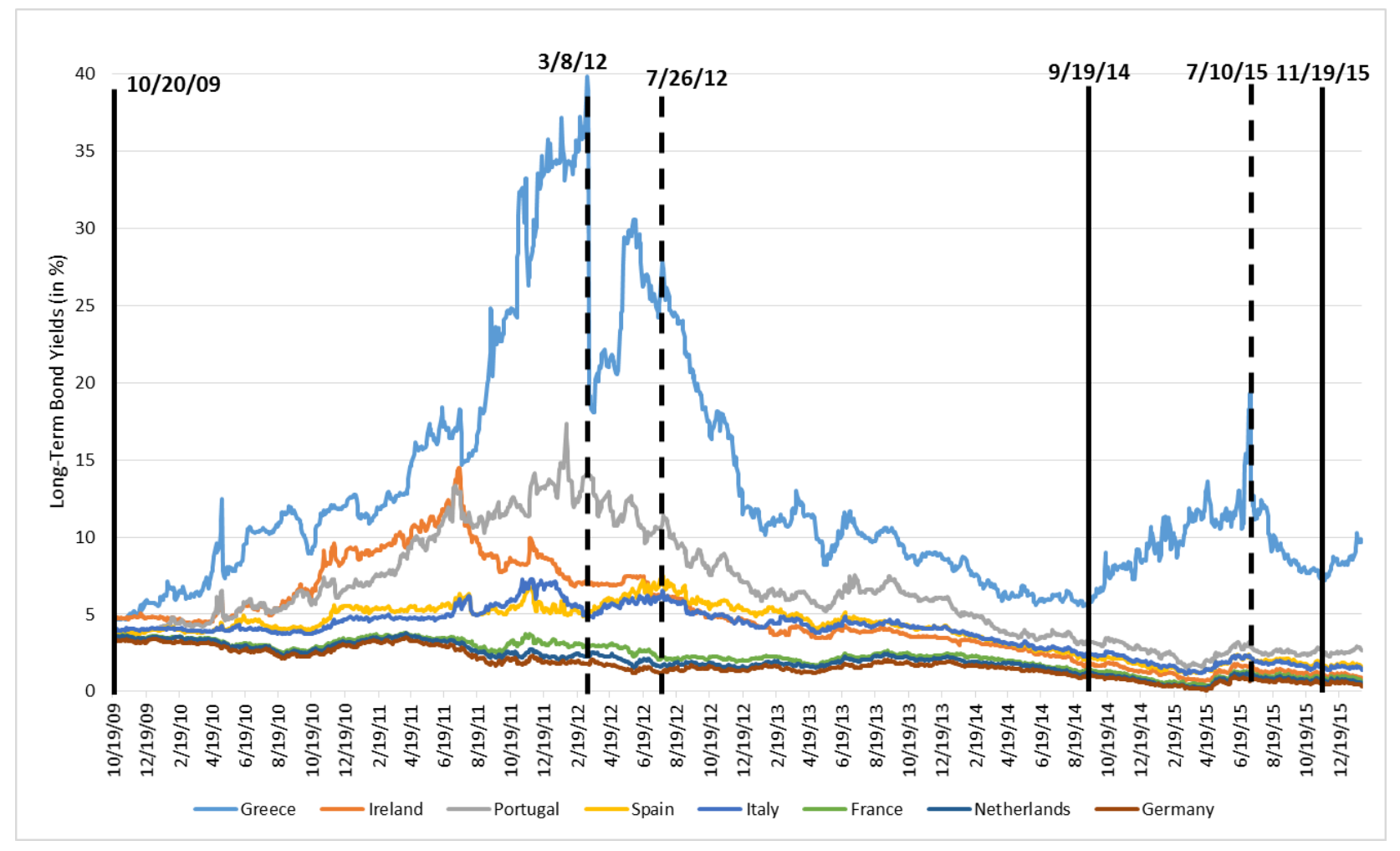

Source: Bloomberg and Investing.com - Stock Market Quotes \& Financial News

Although Greece's GDP growth returned to being positive in the second quarter of 2014, unemployment remained above 26 per cent, and there was increasing political opposition to 'austerity'. Syriza, an anti-austerity party, gained popularity and, after failing to elect a new president in December 2014, the Greek parliament was dissolved and an election was scheduled for January 25, 2015. In his campaign, the leader of Syriza, Alexis Tsipras, announced that he would bring austerity to an end. With Syriza's electoral victory there were increasing fears that Greece would be forced to leave the Euro-zone (Grexit). As Chart 1 reveals, there was a second financial crisis in Greece with yields on Greek bonds reaching a peak in July 2015. It was only after tensions between Greece and its creditors eased, with new austerity measures being passed by the Greek parliament as a 
precursor to receiving the next round of bailout funds in November 2015, which the second crisis appeared to abate.

\section{Crises in Greece and Contagion: The Literature}

There is a large literature that deals with contagion and interdependence. This covers a wide range of countries, time periods and specific crises. In addition to examining interest rates, a considerable portion of the literature has focused on stock markets (see, for example, Bekaert et al, 2014 and Kenourgious and Dimitriou, 2015). Many different statistical correlation techniques have been adopted in order to examine contagion, including dynamic conditional correlation (Engle, 2002; Chiang et al 2007), asymmetric generalized dynamic conditional correlations (Cappiello et al, 2006), and different copula functions (Kenourgiois et al 2011 and Samitas and Tsakalos, 2013). In this paper we use rolling correlations in addition to dynamic conditional correlations (DCC) and a copula function to examine contagion within the Euro-zone.

There are two strands to the existing literature that are relevant to the analysis of the contagion effects of crises in Greece: the first relates to the underlying meaning of 'contagion' and its measurement; the second relates more specifically to the contagion associated with the events in Greece since 2009.

There are various mechanisms through which a financial and economic crisis in one country may affect other countries. Some writers (for example, Forbes and Rigobon, 2002) have considered contagion to refer only to effects not related to fundamentals, frequently called 'pure contagion', while others use the term more broadly to refer to increases in correlations irrespective of what causes them. In this paper we use the concept of contagion in a broad sense to reflect all the ways in which crises in one country may spread and affect other countries. It is important to note, however, that correlation does not necessarily imply contagion. A common shock that affects all countries in a similar way will result in relatively high correlation coefficients, but this is not 
necessarily indicative of contagion. In the context of our study, for example, the statement by Mario Draghi in July 2012 is generally accepted to have had a calming effect on markets and to have reduced risk premia across the board. An observation that bond prices in Greece rose alongside rising bond prices in the other crisis countries does not therefore provide secure evidence that the reduced risk premium in Greece exerted a beneficial contagion effect.

There are a number of studies that have tested for contagion in the case of the first Greek crisis. The results have been mixed. For example, Andenmatten and Brill (2011) examine co-movements of CDS premia in thirty-nine selected countries across the world between October 2008 and July 2010. Applying a bivariate test based on Forbes and Rigobon (2002), they report evidence of contagion. Using a DCC-GARCH model (Engle and Sheppard, 2001), Missio and Watzka (2011) test dynamic correlations between Greece's risk premium and risk premia in five selected countries between December 31, 2008, and December 31, 2010 (Portugal, Spain, Italy, the Netherlands, Belgium and Austria) ${ }^{1}$. They find that yield spreads in Portugal, Spain, Italy and Belgium increased along with those in Greece, but they do not offer any tests of significance.

By separating countries into peripheral and core groups and then using a spatial panel model, Muratori (2014) investigates contagion among selected EMU countries over the period between January 2007 and the end of September 2013; contagion is once again based on the movement in ten-year government bond yield spreads. He reports evidence of contagion especially among peripheral countries, with there being little change in the magnitude of contagion over sub periods.

In contrast to those just summarized, other studies have found more limited evidence to suggest that there was contagion from Greece to the other selected countries during the period of the first Greek crisis. For example, Philippas and Siriopoulos (2013) test for contagion by focusing on six EMU bond markets (the

\footnotetext{
${ }^{1}$ The risk premia were measured as the ten-year government bond yield spreads between the selected countries and Germany. This is the same measurement as we use in the empirical analysis we report in the next section.
} 
Netherlands, Germany, Italy, Spain, Portugal and France) from January 3, 2001, to December 31, 2012. They use two methodologies; a time-varying spillover regime switching model and a time-varying conditional copula model. While they find that bond markets in France, Germany and the Netherlands were negatively affected by the crisis in Greece, they find no significant contagion effect on Portugal, Italy and Spain. They conclude that there is no overall contagion effect.

Pragidis et al. (2015) also look for possible contagion effects from Greece to selected Euro-zone countries (France, Germany, Ireland, Italy, Portugal and Spain) by examining ten-year Greek government bond yields between July 2006 and July 2012. Using a corrected dynamic conditional correlation model, they find, somewhat surprisingly, that the correlations between Greece and the other countries' bond yields decreased after the eruption of the Greek crisis. During the crisis period, only Irish and Portuguese bond yields were significantly correlated with the Greek bond yield and they conclude that there was no general contagion effect.

In this paper we seek to build on the existing literature in several ways. We investigate the contagion effects from Greece to other Euro-zone countries throughout the period 2009-15, and in particular examine whether contagion was more muted in the latter part of the period. We analyze the extent to which Euro-zone markets responded differently to the second crisis in 2015 than they had done to the first one. In this way we specifically test to see whether contagion diminished, with markets treating other Euro-zone countries as being better insulated from events in Greece. Following on from parts of the literature that suggest that there are asymmetries in the response of markets to good and bad news (Caporale et al., 2014; Beetsma et al., 2013; Alfonso et al., 2012) we investigate the extent to which the strength of contagion depended on whether the level of the risk premium in Greece was rising or falling. 


\section{Data and Methods}

Our data set consists of daily observations on 10-year government bond yields for eight Euro-zone countries, France, Germany, Greece, Ireland, Italy, Netherlands, Portugal, and Spain, from $20^{\text {th }}$ October 2009 to $19^{\text {th }}$ November 2015, covering both Greek crises to date. The difference between the 10 -year government bond yields in each of the seven countries and the equivalent German bond yield is used as a measure of the risk premium. Where changes in the Greek risk premium are significantly and positively correlated with changes in the risk premia in the other six countries we conclude that there is prima facie evidence of contagion from Greece to the other Euro-zone member states. ${ }^{2}$

Prior to estimation we pre-tested the data to ensure stationarity of the risk premium and to select the most important break points in the time series. Table 1 shows the set of descriptive statistics used to inform our statistical analysis. Column 2 shows the unit root test results based on the ADF statistics. These confirm that the changes in the risk premia for all six country pairs are stationary across the whole sample. Chart 1 suggests that it is reasonable to place the first Greek crisis as running from $20^{\text {th }}$ October 2009, when the newly elected Greek government revealed the true scale of the budget deficit, until $18^{\text {th }}$ September 2014 . We have the second Greek crisis as running from the $19^{\text {th }}$ September 2014, when the leader of the Syriza party, Alexis Tsipras, announced that he was opposed to austerity and wanted to negotiate in an alliance with other peripheral Euro-zone countries that were in crisis, until $19^{\text {th }}$ November 2015 , when the Greek government passed a new austerity program. These perceived breaks were tested using Bai-Perron structural break tests corresponding to these dates and, as Table 2 shows, the null of no structural breaks is strongly rejected in each case, thus confirming the partition of our sample. In addition an endogenous structural break test gave a single break point on $25^{\text {th }}$ July

\footnotetext{
${ }^{2}$ Of course some of the observed correlations may be due to contagion from events in other countries. Here, however, we follow the assumptions made in most studies that causation runs primarily from Greece. While Granger causality tests were unable to confirm causality from Greece to the other Euro-zone members, this test is particularly unreliable in this context, since, with forward-looking behaviour by agents, causality may seem to run in the wrong direction. In addition, with high frequency data where relationships are time-varying, it is unlikely that Granger causality can even show significant bidirectional causality.
} 
2012, which corresponds exactly with Mario Draghi's "whatever it takes" announcement. Thus the partition of our data set has strong factual and statistical support.

To test for contagion the risk premium of France, Ireland, Italy, the Netherlands, Portugal and Spain are in turn regressed on the Greek risk premium. The correlation coefficient $(R)$, defined as $R_{i}=\beta_{i}\left(\sigma_{G} / \sigma_{i}\right)$, indicates the degree of contagion, where $\beta_{i}$ is the effect of a one unit per cent increase of the Greek risk premium on each of the other $i$ countries' risk premia, and $\sigma_{G}$ and $\sigma_{i}$ are respectively the standard deviations of the risk premium in Greece and in each of the other $i$ countries. The importance of positive contagion is represented by the sign, size and statistical significance of the bilateral correlation coefficient, which is assumed to follow Student's t-distribution such that: $t=R /\left[\left(1-R^{2}\right) /(n-2)\right]^{1 / 2}$ where $n$ is the sample size and the null hypothesis is that $R$ is equal to zero.

An alternative to the simple correlation coefficient is Somers' delta $(d)$ which is a nonparametric measure of the strength and direction of association between an ordinal dependent and independent variables where both variables are monotonic. This is largely the case in our sub-samples when the risk premia are either rising or falling.

One limitation associated with using simple correlations is that it implicitly assumes linearity over the sample. To deal with potential non-linearity in the data, we employ a rolling window technique whereby, as with a piecewise regression, a non-linear time series can be divided up into a number of shorter sub-samples which are more approximately linear. In this case correlation coefficients are computed over rolling fixed window lengths of 5 days and 15 days. An average of these rolling correlation coefficients gives the mean response, allowing for some non-linearity.

Another potential limitation of the simple correlation coefficient is that it is based on the ordinary least squares residual variance being constant across the sample. In the case of non-constant error variances and 
volatility clustering, whereby large changes in the risk premium follow large changes and smaller changes follow small changes, Engle (1982) suggested an ARCH model in which the estimated residual variance is subject to time-varying conditional heteroskedasticity. This multivariate GARCH model has the effect of allowing for some non-linearity between the Greek and the other Euro-zone members' risk premium. From the earlier definition of $R$, intuitively if $\sigma_{G}$ and $\sigma_{i}$ vary over the sample then $R_{i}$ will also vary over the sample. The dynamic conditional correlation model of Engle (2002) not only achieves a large reduction in the number of parameters by specifying univariate conditional GARCH variances $\sigma_{i t}^{2}$ but also generates parsimonious conditional correlation series, $R_{i t}$, for each country pair and the average conditional correlation statistic (DCC $)^{3}$.

Our final correlation test is Student's t-copula. The advantage of a copula is that it is more flexible because it allows the fitting of the dependence structure of the time series separately from the marginal distribution, which means that different marginal distributions can be fitted to different variables. So given two random variables $X$ and $Y$ with continuous marginal functions $F_{x}(x)$ and $F_{y}(y)$, the Sklar Theorem (Sklar, 1959) states that the joint distribution function $F(x, y)$ can be written in the form of a copula function, $C$, such that $F(x, y)=C\left(F_{x}(x), F_{y}(y)\right)$. Therefore the function is the copula of $F(x, y)$ and the distribution is coupled with the marginal distributions $F_{x}(x)$ and $F_{y}(y)$. Thus a copula is a way of representing the dependence structure between $X$ and $Y$. There are, however, a very large number of potential distributions which can be selected; in this paper we chose the bivariate, student t-distribution. This has the advantage of being able to capture high kurtosis, which is present in our data, as shown in Table 1, where the risk premium for all countries exhibits kurtosis. Thus the marginal distributions for changes in the risk premia of Greece, Ireland, Spain and France have heavy tails to the left, while Portugal, Italy and the Netherlands have heavy tails to the right. The Shapiro-Wilk normality test also suggests that we can strongly reject the hypothesis that all variables are

\footnotetext{
${ }^{3}$ As noted by Caporin and McAleer (2013), there are no robust significance tests for this statistic.
} 
normally distributed. In sum, while normal distribution appears not to be the appropriate marginal distribution for our data, the student-t distribution does seem to be an appropriate marginal distribution ${ }^{4}$.

\section{Results, Discussion and Interpretation}

\subsection{Correlations across countries and the two crisis periods}

Over the periods of both crises, changes in the market's perception of risks in Greece, as reflected by changes in Greek risk premia, had a positive, statistically significant and often large effect on risk premia elsewhere in the Euro-zone. We use both a 5-day and a 15-day rolling window, and calculate simple correlation coefficients as well as the DCCs. As shown in Table 3, during both of the crises the 15-day window yielded higher correlations than the 5-day one, although the differences were not large. For the first period, the DCC estimates lay between the two rolling window ones, while the t-copula statistics were the largest for all countries (except Ireland on the 15-day window). For the second crisis, however, the DCC estimates were consistently below the estimates using both the 5 and 15-day windows, although the copula correlation measure was the largest for every country, except France. All four methods show approximately the same patterns. During both the first and second crises the correlations for the four other PIIGS are quite similar. There appears to have been little differentiation among them ${ }^{5}$. The correlations were substantial, typically falling in the range of 0.3 to 0.4 , although the copula measures were marginally higher in a range of $0.4-0.5$.

Generally the differences between the same types of correlations across the two periods were small, with the exception that the 5 and 15-day rolling window correlation statistics tended to be somewhat higher during the second crisis for the 5 and 15-day windows. Both the 5-day and the 15-day windows, as well as the

\footnotetext{
${ }^{4}$ The large, negative skewness on the Greek risk premium is a potential problem because the t-distribution is a symmetric distribution. However, as Cherubini et al (2004) point out a non-central Student t can be used to allow for negative skewness; in large samples this seems to make little significant difference to the marginal estimation.

${ }^{5}$ We take the finding that there is little differentiation among the correlations for the other countries as providing some support for our assumption that the shocks came mainly from Greece.
} 
copula measures of correlation, showed a substantial increase for Portugal in the second period, although the DCC estimates showed little change. This is confirmed by Chart 2, which plots the dynamic DCC statistics for each country relative to Greece over the whole sample. In addition, chart 2 shows that the time-varying pattern of changes in the risk premia of the PIIGS was very similar across the sample. In general, there was no consistency across the methods as to which countries had the largest changes.

A second important finding is that while, as expected, the two core countries in our sample, France and the Netherlands, had much smaller correlations than the crisis countries, as shown in Chart 2, these correlations were also significant and fairly large; the range was between 0.10 to 0.30 , with most observations falling between 0.20 to 0.28 . The correlations suggest that the Netherlands may have been slightly less affected than France during the first crisis with almost no difference during the second one. Likewise, there is little difference in the estimates between the first and second crises, except for the 5-day window in the case of the Netherlands. This showed a substantial increase during the second crisis from what was a very low estimate during the first one.

Given the range of economic circumstances in the other countries we selected, the observed correlations seem likely to reflect broad contagion as we have defined it, and a causal connection running primarily from Greece to the other countries rather than reverse causation. It also seems unlikely that the significant co-movement of risk premia over the entire period can be adequately explained by a series of common external shocks, although this sometimes may have been a factor, such as in the case of Draghi's statement in support of the Euro in July, 2012 which resulted in a general decline in risk premia. The argument that by the time of the second Greek crisis other Euro-zone countries had been able to largely isolate themselves in the eyes of the markets from events in Greece and eradicate or substantially reduce contagion is not supported by our evidence. This may be partly because the underlying institutional structure of the Eurozone did not change between the two crises. While some defensive measures have been taken, most of the 
fundamental changes that have been recommended by many experts as needed in order for the Euro-zone to operate effectively have faced strong political opposition from countries such as Germany (see Bergsten, 2012, Bird, 2012, Eichengreen and Wyplosz, 2016, and Brunnermeier et al. 2016). With little prospect of such reform and with banking systems that have been insufficiently strengthened, it is unsurprising that financial markets continue to regard the Euro-zone as fragile.

As compared with the entire span of the first crisis from October, 2009 to September, 2014, it appears that, for our selected countries and based on the rolling window Pearson correlation coefficients as well as the tcopula measures in Table 3, the contagion from the second Greek crisis was either a little or much larger. It was no lower for any of the countries in our sample, and it is only in Italy, and then only in the case of the 15-day rolling window correlation, that there was no change between the correlation coefficients across the two crises. Table 3 also provides evidence to show that the differences were statistically significant in the cases of Portugal, France and the Netherlands. Interestingly the increases in contagion as between the two crises are largest in the case of one core country (the Netherlands) and one periphery country (Portugal). By contrast the DCC and copula estimates paint a somewhat different picture about the relative sizes of the correlations between the first and second crises. For these, all of the other PIIGS countries showed declines ranging from 0.01 to 0.08 on the DCC measure but an increase on the copula measure of between 0.03 and 0.06 . For France and the Netherlands both DCC and copula measures show a small increase.

While we believe these contrasting results show the importance of checking the robustness of results using multiple methods, we also believe that there is adequate evidence across the methods to support the argument that there were not large differences in the correlations among the other crisis countries during the first and second Greek crises and that the core countries also faced sizeable contagion. The claim that contagion was relatively unimportant during the second Greek crisis is not supported by our evidence. 


\subsection{Contagion during periods of rising and falling risk: Were there asymmetries?}

In this sub-section we briefly examine the extent to which responses to increasing and decreasing risk premia in Greece were symmetrical or asymmetrical. Table 4 distinguishes between periods when risk premia were generally rising and when they were generally falling. Consistent with the behavioral finance approach (see, for example, Bird et al, 2017), during the first crisis both the 5 and 15-day windows show higher correlations during periods when the risk premium in Greece was rising than when it was falling (with the exception of Portugal). The differences are fairly substantial with most differences in the range of 0.06 to 0.08 against average correlations in the range of 0.3 to 0.4 for the crisis countries. Once again, however, the differences using the DCC and copula measures are much smaller and Portugal shows higher correlations during the periods of falling risk premia.

For the period of the second crisis in Greece there is a consistent pattern for Portugal, Italy, Ireland and Spain that reveals higher correlations during times when risk premia were rising. The differences are often fairly substantial, and exist irrespective of the statistical methodology used; they are the largest for the copula measure ranging from 0.13 to 0.22 . For the core countries, France and the Netherlands, the results are mixed. The 5 and 15-day windows show higher correlations during the periods when risk premia were falling, while the DCC and copula estimates show the opposite. Somers' delta correlation analysis, show the same general patterns as the other measures for the second crisis period but reveal no substantial asymmetry during the first crisis.

\section{Conclusions}

Whereas a popular view is that there was little contagion from the second Greek crisis as compared with the first one, we find that there was considerable contagion, broadly defined, during both crises, and that the contagion during the second crisis was at least of the same order of magnitude as during the first one; Pearson 
rolling window correlations and copulas suggest stronger contagion from the second Greek crisis. The notion that core countries became largely exempt from contagion by the time of the second Greek crisis is not supported by the evidence. While less than for the crisis countries (Portugal, Ireland, Italy and Spain), France and the Netherlands also faced substantial contagion during both crises. For the other crisis countries, contagion from the second Greek crisis was little different from that associated with the first Greek crisis. These findings suggest that although the two crises were generated by different types of events, the resulting contagion was not too dissimilar. This in turn implies that a common underlying factor, such as the perceived deficiencies in the institutional structure of the Euro-zone, may have contributed to contagion. The persistence of national macroeconomic imbalances across members of the Euro-zone, along with continuing weaknesses within many national banking systems make the Euro-zone fragile and susceptible to contagion from crises.

While our analysis establishes some important broad facts about the patterns of contagion during the two Greek crises, further research could seek to differentiate between the various types of contagion and could break down the crises into further sub periods. It could also distinguish between common and country-specific shocks as well as the degree of rational versus irrational contagion. Our preliminary examination of periods of rising and falling risk premia suggests that during the Greek crises, and in particular during the second one, some behavioural influences, such as excessive pessimism and confirmation bias, may have been at work. However, the data are not consistent with the claim that markets were highly irrational. ${ }^{6}$

While in this paper we only compare the first and second Greek crises and periods of rising and falling risk premia, there may well be substantial differences in behavior across different sub phases of the crises. Preliminary work we have done, but which we do not report in this paper, suggests this is indeed the case. For

\footnotetext{
${ }^{6}$ Markets may still have deviated substantially from efficiency in other dimensions. There is very strong evidence that they underpriced risk before the crisis and some studies have concluded that markets over priced risk during the crisis. See for example Beirne and Fratzscher, 2013; Bird et al., 2016; Gibson et al., 2012, 2014.
} 
example, contagion appears to have been stronger in the early phase of the second Greek crisis than in the later phase. This is an area of research that warrants further investigation.

The results reported in this paper offer few grounds for believing that contagion from crises in Greece (and elsewhere in the Euro-zone) are a thing of the past, or that Euro-zone governments and EU bodies will develop sufficiently cohesive institutions and policies for dealing effectively with future crises should they occur. One key issue has been the failure (up to the point of writing) to reach agreement on the restructuring of Greek debt, in spite of the IMF's belief that it remains unsustainable. Another one relates to the continuing weaknesses of several national banking systems. Although Euro-zone governments have declared that there will be no further public bailouts of banks, markets may question the credibility of such commitments. Banking crises could then still be perceived as potentially feeding back adversely on countries' fiscal positions. Further crises in markets for both government and private sector debt remain a distinct possibility. The evidence presented in this paper suggests that such crises may continue to have significant contagion effects across much of the Euro-zone. 


\section{References}

Afonso, A., Furceri, D., \& Gomes, P. (2012). Sovereign Credit Ratings and Financial Markets Linkages: Application to European Data. Journal of International Money and Finance, 31(3), 606-638.

Andenmatten, S. and Brill, F. (2011). Measuring Co-Movements of CDS Premia during the Greek Debt Crisis. University of Bern. Department of Economics, Discussion paper 04-11.

Beetsma, R., Giuliodori, M., Jong, F. D., \& Widijanto, D. (2013). Spread the News: The Impact of News on the European Sovereign Bond Markets during the Crisis. Journal of International Money and Finance, 34, 83-101.

Beirne, J., \& Fratzscher, M. (2013). The Pricing of Sovereign Risk and Contagion during the European Sovereign Debt Crisis. Journal of International Money and Finance, 34, 60-82.

Bekaert , G., Ehrmann, M., Fratzscher, M. \& Mehl, A. (2014). Global crises and equity market contagion. Journal of Finance, 69(6), 2597-2649.

Bergsten, C. F. (2012). Why Will the Euro Survive: Confronting the Continent's Half Built House. Foreign Affairs. 91 (5).

Bird, G. (2012). Breaking Up Is Hard to Do: The Euro-zone and the Political Economy of Monetary Disintegration, World Economics, 13 (3) 1-12.

Bird, G., Du, W., \& Willett, T. (2017). Behavioral Finance and Efficient Markets: What Does the Euro Crisis Tell Us? Open Economies Review (forthcoming)

Bollerslev, T. (1986). Generalized Autoregressive Conditional Heteroskedasticity. Journal of Econometrics, 31(3), 307-327.

Brunnemeier, M. K., James, H., and Landau, JP, (2016). The Euro and the Battle of Ideas, Princeton and Oxford, Princeton University Press.

Caporale, G. M., Spagnolo, F., \& Spagnolo, N. (2014). Macro News and Bond Yield Spreads in the Euro Area. DIW Berlin Discussion Papers, no. 1413.

Caporin, M. and McAleer, M. (2013) Ten Things You Should Know About the Dynamic Conditional Correlation Representation. Econometrics, 1 (1), 115-126

Cappiello, L., Engle, R.H., \& Sheppard, K. (2006). Asymmetric dynamics in the correlations of global equity and bond returns. Journal of Financial Econometrics, 4, 537-572.

Cherubini, U., Luciano, E. \& Vecchiato, W. (2004). Copula Methods in Finance. John Wiley: Chichester.

Chiang, T.C., Jeon, B. N. \& Li, H. (2007). Dynamics correlation analysis of financial contagion: evidence from Asian Markets. Journal of International Money and Finance, 26, 1226-1228. 
De Santis, R. (2012). The Euro Area Sovereign Debt Crisis: Safe Haven, Credit Rating Agencies and the Spread of the Fever from Greece, Ireland and Portugal. ECB Working Paper, No. 1419.

Eichengreen, B. and Wyplosz, C. (2016). Minimal Conditions for the Survival of the Euro, Intereconomics, 1, 2428.

Engle, R. (1982). Autoregressive Conditional Heteroscedasticity with Estimates of the Variance of United Kingdom Inflation. Econometrica, 50(4), 987.

Engle, R., \& Sheppard, K. (2001). Theoretical and Empirical properties of Dynamic Conditional Correlation Multivariate GARCH. NBER Working Paper No. 8554.

Engle, R. (2002). Dynamic Conditional Correlation. A Simple Class of Multivariate Generalized Autoregressive Conditional Heteroskedasticity Models. Journal of Business and Economic Statistics, 20, 339-350.

Forbes, K., \& Rigobon, R. (2002). No Contagion, Only Interdependence: Measuring Stock Market Co-movements. The Journal of Finance, 57(5), 2223-2261.

Gibson, H. D., Hall, S. G., \& Tavlas, G. S. (2012). The Greek Financial Crisis: Growing Imbalances and Sovereign Spreads. Journal of International Money and Finance, 31(3), 498-516.

Gibson, H. D., Hall, S. G., \& Tavlas, G. S. (2014). Fundamentally Wrong: Market Pricing of Sovereigns and the Greek Financial Crisis. Journal of Macroeconomics, 39, 405-419.

Giordano, R., Pericoli, M., \& Tommasino, P. (2013). Pure or Wake-Up-Call Contagion? Another Look at the EMU Sovereign Debt Crisis. International Finance, 16(2), 131-160.

Gómez-Puig, M., \& Sosvilla-Rivero, S. (2014). Causality and Contagion in EMU Sovereign Debt Markets. International Review of Economics \& Finance, 33, 12-27.

Kenourgios, D., Samitas, A. \& Palalidis, N. (2011). Financial crises and stock market contagion in a multivariate time-varying asymmetric framework. Journal of International Financial Markets, Institutions and Money, 21(1), 92-106.

Kenourgios, D. \& Dimitriou, D. (2015). Contagion of the global financial crisis and the real economy: A regional Analysis. Economic Modelling, 44, 283-293.

Ludwig, A. (2014). A Unified Approach to Investigate Pure and Wake-Up-Call Contagion: Evidence from the Eurozone's First Financial Crisis. Journal of International Money and Finance, 48, 125-146.

Muratori, U. (2014). Contagion in the Euro Area Sovereign Bond Market. Social Sciences, 4(1), 66-82.

Philippas and Siriopoulos (2013). Putting the "C" into Crisis: Contagion, Correlations and Copulas on EMU Bond Markets. Journal of International Financial Markets, Institutions and Money, 27(C), 161-176.

Pragidis I., Aieli G. P., Chionis D. and Shizas P. (2015). Contagion Effects during the European Debt Crisis: Evidence from the Greek Sovereign Bonds Market, Journal of Financial Stability, forthcoming. 
Samitas, A. and Tsakalos, I. (2013). How can a small country affect the European Economy? The Greek contagion phenomenon. Journal of International Financial Markets, Institutions and Money, 25, 18-32.

Scharfstein, D. \& Stein, J. (1990). Herd Behavior and Investment. The American Economic Review, 80 (3), 465479.

Sklar, A. (1959). Fonctions de repartition à $\mathrm{n}$ dimensions et leurs marges. Publication of the Institute Statistical University, Paris, 8, 229-231.

Truman, B. (1994). Analyst Forecasts and Herding Behavior. Review of Financial Studies. 7(1), 97-124. 
Table 1. Supremum Wald Test for Structural Breaks ${ }^{7}$.

\begin{tabular}{|c|c|c|c|c|}
\hline Dates & 8-Mar-12 & 26-Jul-12 & $19-S e p-14$ & $19-$ Nov-15 \\
\hline $\mathrm{X}^{2}$ & $11.43^{* * *}$ & $24.91^{* * *}$ & $6.95^{* *}$ & $8.76^{* *}$ \\
\hline
\end{tabular}

Note: $* * *$ and $* *$ indicate the significant levels of $1 \%$ and $5 \%$ respectively. $\mathrm{H}_{0}$ : there is no structural break on the specified dates.

Table 2. Descriptive statistics for the whole sample period

\begin{tabular}{|l|c|c|c|c|c|c|}
\hline $\begin{array}{c}\text { Change in risk } \\
\text { premium }\end{array}$ & ADF & $\begin{array}{c}\text { Mean } \\
\text { (in bps) }\end{array}$ & Std.Dev & Kurtosis & Skewness & Normality \\
\hline Greece & $-52.30 * * *$ & 0.344 & 0.72 & 378.46 & -13.68 & $0.84 * * *$ \\
\hline Ireland & $-31.37 * * *$ & -0.062 & 0.13 & 19.27 & -0.20 & $0.89 * * *$ \\
\hline Portugal & $-33.38 * * *$ & 0.090 & 0.20 & 34.04 & 0.83 & $0.89 * * *$ \\
\hline spain & $-33.88^{* * *}$ & 0.041 & 0.11 & 10.47 & -0.33 & $0.94 * * *$ \\
\hline Italy & $-35.09 * * *$ & 0.020 & 0.10 & 10.90 & 0.16 & $0.90^{* * *}$ \\
\hline France & $-33.24 * * *$ & 0.002 & 0.04 & 9.92 & -0.03 & $0.84 * * *$ \\
\hline Netherlands & $-39.28 * * *$ & -0.009 & 0.02 & 12.94 & 0.71 & $0.98^{* * *}$ \\
\hline
\end{tabular}

Note: ${ }^{* * *}$ indicates the significant level of $1 \%$. ADF, $\mathrm{H}_{0}$ : the variable exhibits a unit root and Shapiro-Wilk $\mathrm{W}$-test for normality $\mathrm{H}_{\mathrm{o}}$ : the variable is normally distributed.

${ }^{7}$ As illustrated in Chart 1 in the paper, 8-Mar-12 indicates the end of the rising period in the first Greek crisis; 26Jul-12 indicates the beginning of the falling period in the first Greek crisis; 19-Sep-14 indicates the beginning of the second Greek crisis; $19-N o v-15$ indicates the end of the rising period as well as the beginning of the falling period in the second Greek crisis. 
Table 3. Correlations between Changes' in Risk Premia of Greece and the Other Selected Countries in the First and the Second Greek Crisis.

\begin{tabular}{|c|c|c|c|c|c|c|c|c|c|c|c|c|}
\hline & \multicolumn{4}{|c|}{ 1st crisis } & \multicolumn{4}{|c|}{ 2nd crisis } & \multicolumn{4}{|c|}{$\begin{array}{l}\text { difference between } \\
\text { the } 1 \text { st and } 2 \text { nd crisis (in abs) }\end{array}$} \\
\hline & $\begin{array}{l}\text { 5-day } \\
\text { rolling } \\
\text { window } \\
\text { (mean) R }\end{array}$ & $\begin{array}{l}\text { 15-day } \\
\text { rolling } \\
\text { window } \\
\text { (mean) R }\end{array}$ & $\begin{array}{c}\text { DCC } \\
\text { (mean) }\end{array}$ & t-copula & $\begin{array}{l}\text { 5-day } \\
\text { rolling } \\
\text { window } \\
\text { (mean) R }\end{array}$ & $\begin{array}{l}\text { 15-day } \\
\text { rolling } \\
\text { window } \\
\text { (mean) R }\end{array}$ & $\begin{array}{c}\text { DCC } \\
\text { (mean) }\end{array}$ & t-copula & $\begin{array}{l}\text { 5-day } \\
\text { rolling } \\
\text { window } \\
\text { (mean) R }\end{array}$ & $\begin{array}{l}\text { 15-day } \\
\text { rolling } \\
\text { window } \\
\text { (mean) R }\end{array}$ & $\begin{array}{c}\text { DCC } \\
\text { (mean) }\end{array}$ & t-copula \\
\hline Ireland & $0.34 * *$ & $0.41 * * *$ & 0.37 & $0.39 * * *$ & $0.36 * *$ & $0.42 * *$ & 0.31 & $0.43 * * *$ & 0.02 & 0.01 & 0.06 & 0.04 \\
\hline Portugal & $0.28 * *$ & $0.36 * * *$ & 0.33 & $0.43^{* * *}$ & $0.40^{* *}$ & $0.46 * *$ & 0.32 & $0.49 * * *$ & $0.12^{* * *}$ & $0.10^{* * *}$ & 0.01 & 0.06 \\
\hline Spain & $0.33^{* *}$ & $0.39 * * *$ & 0.37 & $0.40 * * *$ & $0.34^{* *}$ & $0.40^{* *}$ & 0.30 & $0.44^{* * *}$ & 0.01 & 0.01 & 0.07 & 0.04 \\
\hline Italy & $0.30 * *$ & $0.39 * * *$ & 0.36 & $0.40 * * *$ & $0.34^{* *}$ & $0.39 * *$ & 0.28 & $0.43^{* * *}$ & 0.04 & 0.00 & 0.08 & 0.03 \\
\hline France & $0.19 * *$ & $0.26 * * *$ & 0.19 & $0.26 * * *$ & $0.26 * *$ & $0.30 * *$ & 0.20 & $0.28 * * *$ & $0.07^{* *}$ & $0.04 * *$ & 0.01 & 0.02 \\
\hline Netherlands & $0.09 * *$ & $0.18 * * *$ & 0.14 & $0.19 * * *$ & $0.25^{* *}$ & $0.26 * *$ & 0.24 & $0.28 * * *$ & $0.16 * * *$ & $0.08 * * *$ & 0.10 & 0.09 \\
\hline
\end{tabular}

Note: $* * *$ and $* *$ indicate the significant levels of $1 \%$ and $5 \%$ respectively. 
Table 4. Correlations between Changes' in Risk Premia of Greece and the Other Selected Countries in the First and the Second Greek Crisis in the Rising and Falling Periods.

\begin{tabular}{|l|c|c|c|c|c|c|c|c|c|c|}
\hline \multirow{2}{*}{ 1st crisis } & \multicolumn{2}{|c|}{$\begin{array}{c}\text { 5-day rolling } \\
\text { window (mean) R }\end{array}$} & \multicolumn{2}{c|}{$\begin{array}{c}15 \text {-day rolling } \\
\text { window (mean) R }\end{array}$} & \multicolumn{2}{c|}{ DCC (mean) } & \multicolumn{2}{c|}{ Somers' d } & \multicolumn{2}{c|}{ t-copula } \\
\cline { 2 - 12 } & Rising & Falling & Rising & Falling & Rising & Falling & Rising & Falling & Rising & Falling \\
\hline Ireland & $0.38^{* *}$ & $0.34^{* *}$ & $0.45^{* *}$ & $0.40^{* *}$ & 0.40 & 0.36 & $0.27^{* * *}$ & $0.27^{* * *}$ & $0.40^{* * *}$ & $0.42^{* * *}$ \\
\hline Portugal & $0.28^{* *}$ & $0.32^{* *}$ & $0.36^{* *}$ & $0.42^{* * *}$ & 0.32 & 0.38 & $0.26^{* * *}$ & $0.29^{* * *}$ & $0.44^{* * *}$ & $0.46^{* * *}$ \\
\hline Spain & $0.39^{* *}$ & $0.30^{* *}$ & $0.45^{* *}$ & $0.37^{* * *}$ & 0.41 & 0.35 & $0.28^{* * *}$ & $0.24^{* * *}$ & $0.42^{* * *}$ & $0.39^{* * *}$ \\
\hline Italy & $0.35^{* *}$ & $0.29^{* *}$ & $0.44^{* *}$ & $0.37^{* * *}$ & 0.39 & 0.36 & $0.29^{* * *}$ & $0.26^{* * *}$ & $0.41^{* * *}$ & $0.40^{* * *}$ \\
\hline France & $0.24^{* *}$ & $0.17^{* *}$ & $0.30^{* *}$ & $0.24^{* *}$ & 0.21 & 0.20 & $0.18^{* * *}$ & $0.17^{* * *}$ & $0.27^{* * *}$ & $0.28^{* * *}$ \\
\hline Netherlands & $0.13^{* *}$ & $0.06^{* *}$ & $0.22^{* *}$ & $0.14^{* *}$ & 0.15 & 0.15 & $0.14^{* * *}$ & $0.10^{* * *}$ & $0.21^{* * *}$ & $0.15^{* * *}$ \\
\hline
\end{tabular}

Note: ${ }^{* * *}$ and ${ }^{* *}$ indicate the significant levels of $1 \%$ and $5 \%$ respectively.

\begin{tabular}{|c|c|c|c|c|c|c|c|c|c|c|}
\hline \multirow[t]{2}{*}{ 2nd crisis } & \multicolumn{2}{|c|}{$\begin{array}{c}\text { 5-day rolling } \\
\text { window (mean) R }\end{array}$} & \multicolumn{2}{|c|}{$\begin{array}{c}\text { 15-day rolling } \\
\text { window (mean) R }\end{array}$} & \multicolumn{2}{|c|}{ DCC (mean) } & \multicolumn{2}{|c|}{ Somers' d } & \multicolumn{2}{|c|}{ t-copula } \\
\hline & Rising & Falling & Rising & Falling & Rising & Falling & Rising & Falling & Rising & Falling \\
\hline Ireland & $0.36 * *$ & $0.35 * *$ & $0.41 * *$ & $0.44 * *$ & 0.33 & 0.28 & $0.27 * * *$ & $0.22 * * *$ & $0.48 * * *$ & $0.26 * *$ \\
\hline Portugal & $0.41^{* *}$ & $0.38 * *$ & $0.48^{* *}$ & $0.39 * *$ & 0.35 & 0.26 & $0.30 * * *$ & $0.26 * * *$ & $0.53^{* * *}$ & $0.40 * * *$ \\
\hline Italy & $0.35 * *$ & $0.30 * *$ & $0.43^{* *}$ & $0.30 * *$ & 0.31 & 0.21 & $0.29 * * *$ & $0.24 * * *$ & $0.48 * * *$ & $0.31 * * *$ \\
\hline France & $0.25 * *$ & $0.29 * *$ & $0.28 * *$ & $0.33^{* *}$ & 0.22 & 0.18 & $0.18 * * *$ & $0.19 * *$ & $0.30 * * *$ & $0.21^{*}$ \\
\hline Netherlands & $0.22^{* *}$ & $0.30^{*}$ & $0.25 * *$ & $0.27^{* *}$ & 0.24 & 0.23 & $0.20 * * *$ & $0.15^{* *}$ & $0.32 * * *$ & $0.17^{*}$ \\
\hline
\end{tabular}

Note: ${ }^{* * *},{ }^{* *}$ and $*$ indicate the significant levels of $1 \%, 5 \%$ and $10 \%$ respectively. 
Chart 2. Dynamic Conditional Correlations between Greece and the Other Sample Countries during the Entire Sample Period.

Dynamic Conditional Correlation between Ireland and Greece

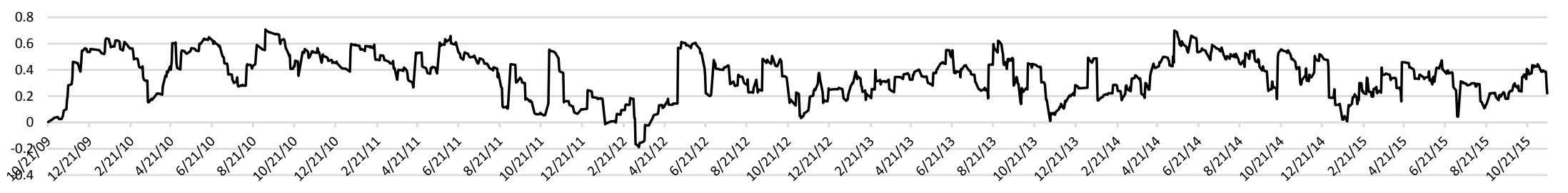

Dynamic Conditional Correlation between Portugal and Greece

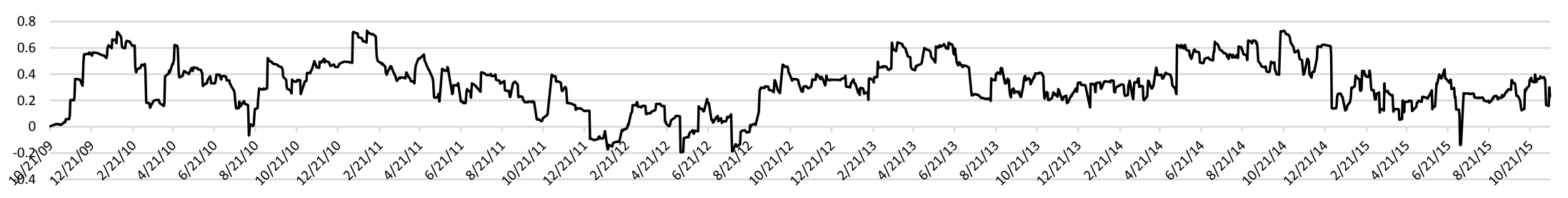

Dynamic Conditional Correlation between Spain and Greece

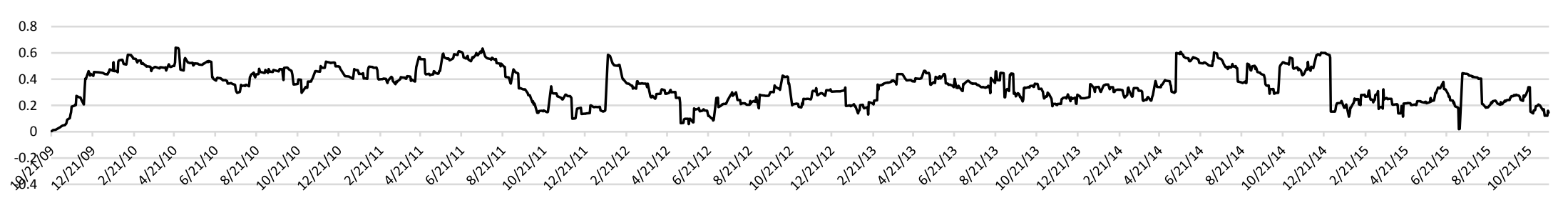

Dynamic Conditional Correlation between Italy and Greece

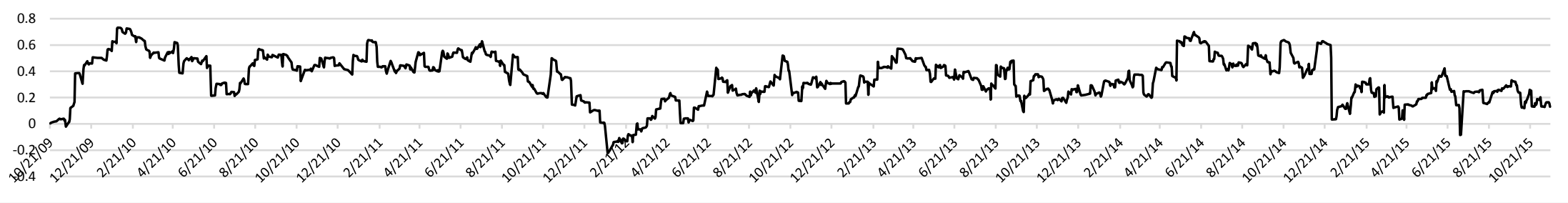


Dynamic Conditional Correlation between France and Greece

0.8

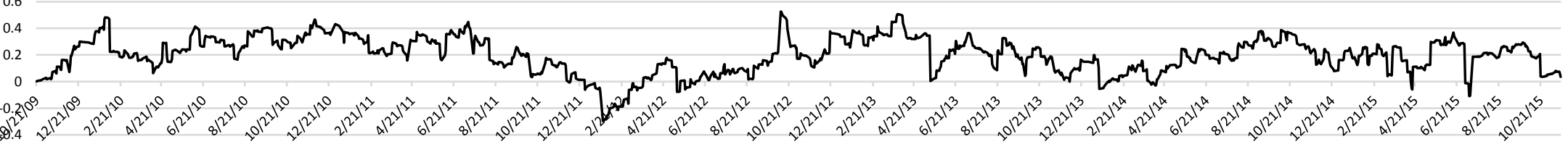

Dynamic Conditional Correlation between Netherlands and Greece

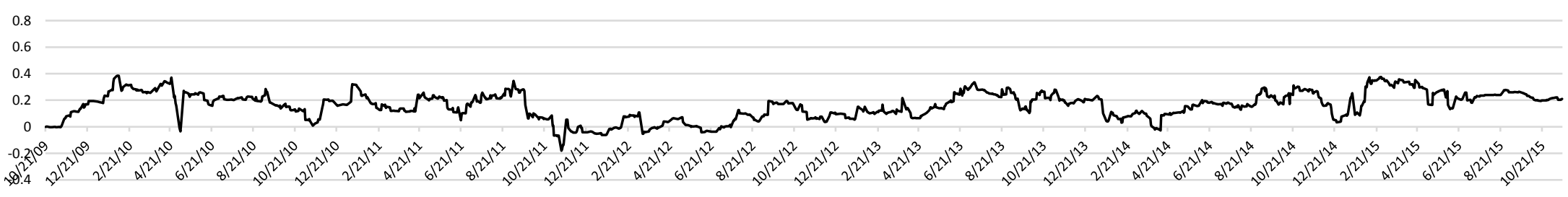

24 